\title{
A Study on the Accounting Education Culture of the University of Saint Louis, Philippines
}

\author{
Randell Rellin ${ }^{1}$, Rizza Joice Pataueg ${ }^{1}$, Renella Pineda ${ }^{1}$, Josephine Sabalo ${ }^{1}$, Mary Antonette Siazon ${ }^{1}$, \\ Darin Jan Tindowen", Karen Joy Catacutan,"* \\ ${ }^{1}$ School of Accountancy, Business and Hospitality, University of Saint Louis, Philippines \\ ${ }^{2}$ Center for Social Innovation, Local Knowledge and Educational Research, University of Saint Louis, Philippines \\ ${ }^{3}$ Center for Business Research and Development, University of Saint Louis, Philippines
}

Received February 25, 2020; Revised March 26, 2020; Accepted May 13, 2020

Copyright $\bigcirc 2020$ by authors, all rights reserved. Authors agree that this article remains permanently open access under the terms of the Creative Commons Attribution License 4.0 International License

\begin{abstract}
Holistic accounting education is a function of not only the lectures and consumption of academic materials but more importantly, it is a function of all the practices and beliefs that collectively comprise an accounting culture. This study aimed to define and provide concrete context on the accounting culture of the University of Saint Louis Tuguegarao. Forty-three Informants comprised of senior students enrolled in the accountancy program were interviewed in the study all under the umbrella of descriptive qualitative research design. Four (4) clustered themes emerged from the current study: (1) Accounting Culture manifested through Academic Competitiveness, (2) Accounting Culture manifested through the Strong Sense of Belongingness, (3) Positive Elements of the Accounting Culture and the (4) Negative Elements of the Accounting Culture. Furthermore, it is concluded that while there were several negative aspects in the existing accounting culture like a source of stress and social divide, the overall response of the Informants were in favor of accounting culture being perceived as an effective affair with respect to its being a gateway to holistic formation and the enhancement of student competence.
\end{abstract}

Keywords Accounting Culture, Accounting Education, Accountancy, Accounting System

\section{Introduction}

Educational culture is not something that starts and ends in the classroom. It is known only when practicing within the fragmented circles of local and national, and of classroom, school, government, and state, and only when one constantly moves back and forth between these, exploring the way in which what teachers and students do in classrooms reflects the values of the wider society (Boag-Munroe, 2010). Educational culture is defined as a locally contextualized collection of educational beliefs, philosophy and practices that aim to aid student learning and growth. It is comprised of not only the classroom sessions and the lecture method but also the co-curricular and extracurricular activities. This culture includes how students are engaged by the school system to do tasks that would snowball to their overall formation and development. Narrowing this definition down to only the accounting sector of education, we get the baseline definition of what this research will be working with.

In the Philippine context and with respect to accounting education, national passing rates have been declining year on year and it alarms educational institutions to produce more accounting professionals as this might be indicative of the institutions' inability to adapt to changes in the industry.

As accounting education is part of the universities ' hierarchical structure and includes all the disadvantages of this hierarchical structure, the pace of reaction to new innovations is reduced (Celik \& Ecer, 2009). Moreover, educators are also alarmed as these rates might also be representative of the quality of accounting education in the Philippines. One scenario may be that accounting educators have a responsibility to help prepare students to make the transition from overwhelmed high school seniors to professional service team members. It is incumbent upon accounting educators to prepare students to be competitive in the unfolding economic future (Kermis, 2011).

Major proponents and advocates of accounting education call for the modification on current practices and integration of new and innovative learning methodologies to stimulate the recovery in terms of volume of CPAs being produced. 
In the modern paradigm, teachers are considered facilitators and mainly act as guides for their students. Today's teaching approaches have to provide opportunities for self-development and combine learned material with real world experiences. Teaching tools such as interactive case studies, simulations and games, and teamwork have been stated to be off high importance to help accounting students adjust to the real-world challenges they will face as accountants (Kermis 2011).

Accounting educationalists are therefore responsible for developing programs that, while remaining true to their academic credentials, often meet the requirements of accountancy training bodies and employers hiring accounting graduates. To this end, accounting educationalists are well-placed to tailor the learning outcomes of their undergraduate programs to meet the expectations of the accountancy profession (Ballantine \& Larres, 2009).

With respect to the data subject for the research conducted, the University of Saint Louis Tuguegarao is one of the top performing schools in the country for the past five years in terms of the accountancy program. The accountancy program of the University of Saint Louis Tuguegarao is known for the high attrition rates in the first two undergraduate years, where, students are mandated to adapt to the pre-existing culture; otherwise, the program will not allow them to continue with accountancy. In the past two school years, only around twenty-five percent (25\%) of the total students who enrolled in the accountancy program were able to make it through and graduate with the degree of Bachelor of Science in Accountancy. However, even considering this rigorous student screening system, the school was still affected with the recent decline in the national passing rates, with only approximately $40 \%$ of students passing the national board exams.

Accounting education and the ways to improve it have been a great concern and a big challenge to the University of Saint Louis, one of the universities in the Northern Philippines, especially the university provides national topnotchers in the Certified Public Accountants (CPA) Board Examinations through the years. It is therefore important for the university and the Accounting educators to facilitate high level of accounting education among the students to achieve better academic and professional success (Villamar, Gayagoy, Matalang \& Catacutan, 2020).

Consistent with the above discussions, this research aimed to identify, assess and evaluate what practices and programs are implemented at this time and subsisted concurrently for the accountancy program; to compose and comprise the accounting education culture of an institution offering an Accountancy program. This research is predicated on the fact that while specific practices might lead to better performance, the greater environment in which those specific practices are implemented are just as important to consider. Academics and professionals have become increasingly concerned about improving the quality of undergraduate education in recent years. One way institutions can improve the learning experience of students is through well-structured course structure which might include well defined syllabi, internship program, case study, use of online tools and financial analysis software (Lai, et al., 2009). However, most of these studies emphasize mostly on individual and specific practices that resulted in favorable results. None of these studies tapped into the general whole of the practices being implemented by institutions. As stated by Celik \& Ecer (2009), the sustainability of competitive advantage depends on the quality of education. This statement is true for almost all but especially developing countries. It is needed to eliminate barriers in front of efficient education system to educate people in a more appropriate way. The first step to resolve the problems is to determine the components of education system. This study aims to conceptualize the meaning of "Accountancy Culture" so as to encompass the Accounting system, said by Celik \& Ecer (2009), and all practices that are included in it, then, can be further studied to identify correlations with other variables and be used for any further purpose in future studies. With this, researchers aimed to explore and obtain a deep understanding about accountancy culture of the University of Saint Louis Tuguegarao, and how it is manifested in the accountancy program and what components/features/relevant factors comprise it.

The purpose of this study is to determine the scope of accounting culture, and to that extent, contribute to the greater body of knowledge on accounting education. This will affect the accountancy students, educators, and all persons involved in the accountancy program as this research, at its completion, would provide a shift in the perspective of curriculum design towards more of a sustainable student-based learning from the more traditional classroom approach. This study will benefit the students in a way that a concrete concept of accounting culture will help them identify and pinpoint which of its components positively or negatively affects them. For educators and academic institutions, this could spark creativity in the implementation of more innovative wellbeing-focused teaching approaches that would improve the overall learning atmosphere of all people involved.

\section{Materials and Methods}

The study utilized descriptive-qualitative research design. The research informants were the existing 5 th year accountancy students of University of Saint Louis for the school year 2019-2020. There were a total of 43 informants of varying characteristics, academic standing and preference. The number of informants fulfilled the rule on data saturation for a qualitative research design. The 
researchers conducted the study inside the University. They interacted with the 5th year students studying Accountancy. Though the interview was based on a systematically designed series of interview questions, the interview proper for each informant was conversational by execution, asking first what culture is for them, eventually leading to the intent of the interview. The researchers interviewed a total of 43 students asking their opinion about culture in general, accounting culture and its characteristics and the effects of this culture to them with respect to their experience. The data gathered from the research tool were analyzed through thematic analysis. The data are examined one by one and categorized into themes which they belong.

Furthermore, in ensuring rigor, the researchers went back to the informants for the aggregated and analyzed results. This ensures that the analyses are the same with what the informants conveyed during the interview sessions.

\section{Results}

This research study explored the perceptions of students on the accounting culture. After a careful review of the Informant's answers and a careful analysis of the interview transcripts, commonalities were clustered together and the researchers came with major themes. These were: (1) accounting culture manifested through academic competitiveness and strong sense of student belongingness, (2) positive elements of accounting culture and (3) negative elements of accounting culture.

\section{Theme 1: Accounting Culture of the University of Saint Louis}

The Informants define and describe their own idea of the existing accounting culture based on their experiences as accounting students. The prevalent theme common to majority of responses narrowed down to the manifestation of academic competitiveness in the accounting culture.

\begin{tabular}{|c|c|c|c|}
\hline Observation & Frequency & Percentage & Rank \\
\hline Academic Competitiveness & 29 & $67.44 \%$ & 1 \\
\hline $\begin{array}{c}\text { Strong Sense of Student } \\
\text { Belongingness }\end{array}$ & 26 & $60.47 \%$ & 2 \\
\hline
\end{tabular}

A. Accounting Culture manifested through Academic Competitiveness

Accounting culture hones the skills of the accounting students through the spirit of academic competitiveness or the concept of maintaining an edge over another or establishing habits based on what others, in the same group, are doing to avoid being left behind. This discipline of maintaining accountability over one's own circumstances is one of the major highlights of the accounting culture which according to the Informants has affected them in some way throughout their entire college life. Academic competitiveness is also a function of the strategies implemented in the accounting program. Teaching strategies of professors were also cited as factors affecting the way students compete with each other

Some of the verbalizations are as follows:

Informant 2: "Yung culture ng mga Accountancy o yung mga nasa department ng SABH, parang more competitive sila parang very disiplinado sila, very studious sila. Yung araw-araw parang kailangan mong nakabasa, kung hindi ka nakabasa ng lesson mo ngayon, mapag-iiwanan $\mathrm{ka}$. Nasa high standard lagi yung mindset. Super strict din sila sa quizzes or exams, no sign of cheating. Makikita mo sa mga estudyante na ayaw nilang magpatalo sa isa't isa." [As for the culture of the Accountancy students or those in SABH department, they are more competitive, disciplined and very studious. You have to read every day or you'll be left out. Their mind set is of high standard. They are also strict during exams, there's no sign of cheating. You can see that they don't want to lose from one another.]

Informant 8: "Questioning mind--- we tend to be detectives of financial statements and information. Innovative - settling for less is a sin. Grade conscious---we want to be excellent in every subject be it minor or major. Dreamer--- always yearning for the bright future."

Informant 15: "Being competitive, not in a destructive way where you don't mind others, but that strong desire to be the best while helping each other hand in hand.

B. Accounting Culture Manifested through the Strong Sense of Belongingness among Students

In light of their descriptions and definitions of accounting culture, Informants provided what features/factors/components comprise it based on their understanding of the concept. Strong sense of student belongingness stood out as the secondary commonality across their responses. Accounting culture maintains the idea that people are social beings and therefore must not be hindered from interacting with other people in the group in the pursuit of individual or common benefit and fulfillment

The Informants contend that one major example or practice that makes up the accounting culture are the activities with academic peers across all year levels. These would be the activities like writing letters for those about to take the board exams and conducting the aforementioned Student Study Group Program (SSGP) activity.

Some of the verbalizations are as follows:

Informant 3: "Isa sa mga naappreciate ko is gumagawa tayo ng mga letters para sa mga kuya nating magtetake ng board exam. I find it significant, hindi lang sa buhay ko na nagsulat kundi sa buhay din ng makakabasa nun. Malay natin isa tayong dahilan sa success nila. Naapreciate ko din yung pagpapamusic ng mga professors during exam in such a way na tinetest tayo kung hanggang saan yung focus natin. Is a pang example is yung SSGP, naapreciate ko 
yung willingness ng mga kasama natin na magturo. ” [One that I appreciate is the letters we give to our seniors who will be taking the board exam. I find it significant not just for me who write but also for the one who will read it. We just don't know, we are one of the reasons of their success. I also appreciate it when our professors play music during exam, it is as if they're testing how long can we focus on what we are doing. Another is the SSGP, I appreciate the willingness of our classmates to teach.]

Informant 7: "I believe the generosity of different students to their junior in achieving their dreams especially the alumni who are already CPAs in giving assistance to their adings in taking board examinations which is consistently being done throughout."

Informant 35: "One of the things nan appreciate ko din sa Junior Philippine Institute of Accountants (JPIA) is yung pagbubuild nila ng relationship ng mga students yung pag establish nila ng SSGP ganun, yung mentor mentee buddy system. Siguro malaking factor din para sakin yung pagiging emotionally supportive ng mga instructors natin kasi despite nay un na nga lagi nila tayong binibigyan ng drills and all, pag napapansin naman nilang nahihirapan yung mga students, nagaadjust na din sila and in addition to that nagbibigay pa sila ng advise. Yung ano din, yung rosary rally, nakakabuildup yung ng morale para sa mga CPALE takers---maganda din yun" [One of the things I appreciate about Junior Philippine Institute of Accountants (JPIA) is the way they implement activities like SSGP and mentor-mentee buddy system to build the relationships between students. Another major factor for me is the emotional support provided by our instructors. Despite the fact that they give frequents assessments, whenever they sense that students are already finding it difficult, they adjust and sometimes they would also give advice. Another would be the rosary rally for it builds up the morale of those who will be taking the CPALE.]

\section{Theme 2: Positive Elements of the Accounting Culture}

The informants expressed positive elements of the accounting culture of the university based on their own experiences as accounting students. The theme common to majority of responses reflects that accounting culture enhance student competence and promotes holistic formation.

\begin{tabular}{|c|c|c|c|}
\hline Observation & Frequency & Percentage & Rank \\
\hline $\begin{array}{c}\text { Enhancing Student } \\
\text { Competence }\end{array}$ & 27 & $62.79 \%$ & 1 \\
\hline $\begin{array}{c}\text { Promotes Holistic } \\
\text { Formation }\end{array}$ & 24 & $55.81 \%$ & 2 \\
\hline
\end{tabular}

\section{A. Enhancing Student Competence}

Professionalism being the targeted bottom line of accounting education, the accounting culture complies with the standard of being able to produce quality graduates through the implementation of the policies, practices and procedures geared to enhance the competence of the students. Around sixty two percent $(62 \%)$ of the Informants claimed that the accounting culture does touch their competence through not only external influence but also internal adaptation to the changing circumstances. According to the accountancy students, the catalysts for them to act are the challenges which form part of the accounting culture. These challenges, according to students, tend to motivate and inspire them to improve willingly and therefore, minimize the resistance for the students to do better.

Some of the verbalizations are as follows:

Informant 1: "Nagiging globally competent sila. Parang ito yung baon nila para maka at par din sila sa iba." [They become globally competent and they are used to being at par with others.]

Informant 38: "When students adapt this culture, they become more inspired to develop their abilities and skills. They strive for excellence and become more active and competitive. Students also have discipline in managing their time."

Informant 43: "Sa mockboards, drills, pretests and quizzes, it prepares the student for the CPA boards. Students are nahahasa sa mga difficult problems and are being expose to challenging problems. Sa SSGP and buddy system, it is very helpful for the lower years for it suffice the kulang na discussion of the teachers for a better understanding of the students sa lesson." [In mockboards, drills, pretests and quizzes, it prepares the student for the CPA boards. Students are trained with difficult problems and are being exposed to challenging problems. In SSGP and buddy system, it is very helpful for the lower years for it suffice the insufficient discussion of the teachers for a better understanding of the students with the lesson.]

\section{B. Promotes Holistic Formation}

Consistent with the previous sub-theme of well-rounded development, accounting culture is forward looking in the sense that, it aims to put students in a conducive environment or position of strength to become competent professionals in the future. Around fifty five percent (55\%) of the Informants shared the idea that the prevalent accounting culture helps them to be versatile and flexible not only in the classroom but potentially in the bigger professional environment after schooling. According to them, through the values, concepts and process inculcated in them through the accounting culture, they've developed a sense of collaboration which they contend to be a contributor to them being able to deal with the various challenges in accounting as a whole.

Some of the verbalizations are as follows:

Informant 8: "These make us versatile, innovative, to play by the rules but with off the grid vision. These make us collaborate and strive for better outcomes."

Informant 20: "Maganda yung effects kasi more than academics, nagiging well-rounded individuals tayo." [One 
of the positive effects is that more than academics, the students became well rounded individuals.]

Informant 41: "It helps students to be the best version of themselves not just in class but in the business world in the future."

\section{Theme 3: Negative Elements of the Accounting Culture}

The informants also stated some of their own experiences on the accounting culture of the university and these extract the negative elements of the accounting culture of the university. To which, the themes summarized that accounting culture in the university is a source of student stress and it contributes to social divide.

\begin{tabular}{|c|c|c|c|}
\hline Observation & Frequency & Percentage & Rank \\
\hline Source of Student Stress & 21 & $48.84 \%$ & 1 \\
\hline Contributes to Social Divide & 18 & $41.86 \%$ & 2 \\
\hline
\end{tabular}

\section{A. Source of Student Stress}

One of the drawbacks of accounting culture is its lack of a limit given that there can be multiple activities which can be implemented simultaneously. This apparent activity overload breeds negative mental effects to students also in light of the degree of focus required in the accounting profession. The Informants said that while activities are good, too much of it proved to be detrimental to their process. Moreover, the simultaneous occurrences of these activities meant confusion for them in terms of what to prioritize doing for the moment. In light of these, students are prone to decision fatigue which, at stressful times, impairs their focus and gets ahead of their better judgment.

Some of the verbalizations are as follows:

Informant 8: "Sleep deprivation and unfriendly competitiveness"

Informant 30: "Na ppressure ka. Pressured ka lagi na parang nababaliw ka na kasi every night parang iniisip mo, "alla hindi ako nag-aral", na parang may negative effect 'yun sa mood mo, sa emotional and mental being mo." [The pressure was brought by it. The thoughts of not being prepared may affect moods negatively, even our emotional and mental being.]

Informant 42: "It would put more pressure on the part of the student to always study resulting to over fatigue and mental stress. Properly schedule school work and personal activities"

\section{B. Contributes to Social Divide}

Accounting culture, though with good intent to promote student development, has the drawback of classifying students through a particular metric which, in turn, promotes discrimination between and across student groups. According to the students, some students or student groups carry with them some privileges which are not available to other students. These privileges, according to them, once they become apparent, establish distinction among students. These distinctions, in turn, through the passage of time, have formed part of the accounting culture and have impacted the students negatively in terms of their ability to cope and stand confidently in the social environment.

Some of the verbalizations are as follows:

Informant 1: "Nakafocus lang sila sa mga matatalino." [They only focus on the top-performing students.]

Informant 2: "Sa sobrang competitive nga, may nafoform na groups at nag-aaway-away sila." [Because of so much competition, they tend to form groups and misunderstandings arise.]

Informant 10: "Some students are not given much attention since there are a lot of them that have talents but only those that have connection to educators shine. Sometimes the senior students don't take the task of teaching freshmen very seriously for the reason that they have important matters to attend to and the latter are being forgotten."

\section{Discussion}

This research study grasps the informants' perception of the Accounting Culture which can be encapsulated in the three (3) major themes: (1) Accounting culture manifested through academic competitiveness and strong sense of belongingness, (2) positive elements of accounting culture and (3) negative elements of accounting culture.

\section{Accounting Culture Manifested through Academic Competitiveness}

On the manifestation through academic competitiveness, other related literatures have stated that the academic competitiveness is a necessary attribute of accounting education. The effect of competition between occupational segments on occupational professionalization is explored with data on accountancy developments in Canada. It is shown that intra professional competition is an important factor directing and pacing the professionalization of accountancy defined in terms of educational standards, the symbolic attributes of professionalism and achievement of occupational licensing (Richardson 2009).

With respect to the results of the study, the accounting culture of the university is manifested through the prevalent attitude of students toward their academics. Most of the interviewees state that practices like reviewing before entering the classroom and active participation in academic competitions like National Accounting Quiz Showdown (NAQDOWN), Annual Regional Convention (ARC) and Regional Midyear Convention (RMYC) are not uncommon; and with the culture of accountancy in the university, it is even widely encouraged. Additionally, according to the interviewees, the wide acceptance of the 
SSGP represents the interest of the students in the accountancy program in gaining that competitive advantage in terms of academic advancement. This concept is further bolstered through the practice of benchmarking grades between students as a relative measure of class standing. With all these said, the interviewees state that academic competitiveness bring forth positive and negative effects depending on the context by which it is demonstrated.

\section{Accounting Culture Manifested through the Strong Sense of Belongingness}

The informants in the study cited various factors contending that they characterize their idea of accounting culture. Most of them cited activities like SSGP, AASC and the teaching strategies as practices in the accounting culture that is distinct in the accountancy program of the USL. This is consistent with the concepts mentioned in related studies. It is recognized that teaching methods can influence the development of several social intellectual abilities such as: cooperation, leadership, responsibility, self-confidence, independence, ability to make decisions and communication skills.

Moreover, similar studies affirm the idea that the accounting culture leads to the holistic development of students (Biesta, 2011, Buckhaults and Fisher, 2011). On the manifestation through the strong sense of student belongingness, the Informants have said that through the activities, interaction is imperative, and they were able to experience the sense of family that is gradually being established with the passage of time. When asked, they often answered with reference to the activities like SSGP. This is somewhat similar with the concepts which are discussed in similar studies. The study of Kariyana et al. revealed that even educators are very positive about learners' participation in co-curricular activities. Feelings of belonging to school among students had been shown to be associated with academic engagement. The guidance from the parents and the teachers indirectly affect the performance of the students (Villalobos, et.al., 2016).

\section{Positive Elements of Accounting Culture}

The informants in the study provided the instances by which they are positively affected by the accounting culture of the University of Saint Louis Tuguegarao. The bottom line of their responses primarily focused on two (2) important sub-themes: the enhancement of student competence and well-rounded student development.

\section{A. Enhancement of Student Competence}

Within the context of this research, the Informants frequently cited activities like the Student Study Group Program (SSGP) where students assist and interact with one another through intellectual and academic discourse. In the same manner, Informants argued that these practices and activities that they cited promoted academic competitiveness, which in turn, they argued, helps them to improve not only their performance but also their internal factors like motivation and versatility as an accounting student. The well-built and well-applied peer assessment will be able to improve learners' cognitive and social skills which make them successfully interact with other people in the daily life (Rochmiyati, 2013).

\section{B. Well Rounded Student Development}

This is also somewhat related to the sub-themes of enhancement of student competence and well-rounded development as the Informants argues that academic competitiveness preceded their own academic improvements and general standing. In other studies, it is generally agreed that motivation influences student performance and learning. Research has found that tying accounting concepts to career applications can be used successfully in introductory accounting classes. In addition to accounting principles, the more students understand professional presentation skills that can be applied to their careers, the greater their participation and enthusiasm in the class will be. They will also show a greater commitment to becoming an accounting professional (Turner, Lesseig \& Fulmer, 2006).

\section{Negative Effects of Accounting Culture}

For the negative effects of accounting culture, the results of the study boiled down to accounting culture being a source of students' stress and a contributory factor to social divide among students.

\section{A. Source of Student Stress}

On the concept of accounting culture being a source of student stress, it was found that stress was also a function of academic competitiveness and other factors that accounting students had to face in their day-to-day dealings. Several studies have examined the effect of perceived stress on academic performance (Lloyd, Alexander, Rice \& Greenfield, 1980; Pritchard \&Wilson, 2003; Sandler, 2001; Wintre \& Yaffe, 2000). The Informants also affirmed that too much of the academic competitiveness leads them to succumb to mediocre results as sometimes, it was almost impossible to cope with the expectations in the accounting culture. The old model will no longer achieve the desired outcomes for any of the three parties in the highly competitive environment of finding and cultivating the "best and brightest" sought by both higher and accounting profession: the students, the industry and the educational institutions. Based on previous research, a laboratory experience was created to provide an environment where soft skills may be developed without diminishing the attention to accounting theory and technical skill development (Kermis, 2011). 


\section{B. Cause of Social Divide}

With respect to accounting culture being a cause of social divide, informants contended that through unreasonable metrics, students, are being grouped in a way that a culture of divisiveness is being promulgated although unintentionally. The Informants went so far saying that these social divide made it also harder for them to cope, especially in light of the culture of academic competitiveness being apparent in the system. By and large, accounting education continues to be constrained within narrowly defined, but mis-conceived, disciplinary boundaries, focusing on the techniques and "skills" of accounting practice (Boyce, 2004).

\section{Conclusions and Recommendations}

This study concludes that the accounting culture that exists in the University of Saint Louis Tuguegarao is manifested through academic competitiveness and strong sense of student belongingness; it also exhibits positive effects such as enhancing student competence and promoting holistic formation; lastly, it also shows negative effects such as being source of student stress and it contributes to social divide.

In light of the recent improvements in the curriculum of the accountancy program in the Philippines presently experienced by the second and first year students, the researchers recommend that consideration be given to replicating the study on accounting culture but with the informants incorporating already the next batch of accountancy students in the University of Saint Louis Tuguegarao.

Moreover, in light of the presence of negative elements in the accounting culture of the University, the researchers recommend any possible solution or remedy to be initiated by those who exercise control over the accountancy program which can eliminate, if not, at least help mitigate the effects of these negative elements as described by the informants of this research.

\section{REFERENCES}

[1] Buckhaults, J., \& Fisher, D. (2011). Trends in accounting education: Decreasing accounting anxiety and promoting new methods. Journal of Education for Business, 86(1), 31-35.

[2] Ballantine, J., Larres, P. (2009). Accounting undergraduates' perceptions of cooperative learning as a model of enhancing their interpersonal and communication skills to interface successfully with professional accountancy education and training. Accounting Education: An International Journal, 18(4-5), 387-402. DOI: 10.1080/09639280902719366

[3] Biesta, G. (2011). From learning cultures to educational cultures: values and judgments in educational research and educational improvement. International Journal of Early Childhood, 43(3), 199-210.

[4] Boag-Munroe, Gill. (2010). Educational theories, cultures and learning by Harry Daniels; Hugh Lauder; Jill Porter; Sarah Hartshorn. British Educational Research Journal. 36. 692-694. 10.2307/27823640.

[5] Boyce, G. (2004). Critical accounting education: teaching and learning outside the circle. Critical perspectives on Accounting, 15(4-5), 565-586.

[6] Celik, O., Ecer, A. (2009). Efficiency in accounting education: evidence from Turkish universities. Critical Perspective in Accounting. 20. 614-634

[7] Kermis, G. (2011). Professional presence and soft skills: a role of accounting education. Journal of Instructional Pedagogies. 1-10

[8] Lai, M. M., Kwan, J. H., Kadir, H. A., Abdullah, M., \& Yap, V. C. (2009). Effectiveness, teaching, and assessments: Survey evidence from finance courses. Journal of Education for Business, 85(1), 21-29.

[9] Lloyd, C., Alexander, A. A., Rice, D. G., \& Greenfield, N. S. (1980). Life events as predictors of academic performance. Journal of Human stress, 6(3), 15-25.

[10] Pritchard, M. E., \& Wilson, G. S. (2003). Using emotional and social factors to predict student success. Journal of college student development, 44(1), 18-28.

[11] Richardson, A. J. (2009). Professionalization and intraprofessional competition in the Canadian accounting profession. Work and Occupations, 14(4), 591-615.

[12] Rochmiyati. (2013). Peer Assessment Model in the Elaborative Collaborative Learning of Integrated Social Science in Junior High School. Education Research and Evaluation Journal, 17 (2), 333-346.

[13] Turner, K. G., Lesseig, V. P., \& Fulmer Jr, J. G. (2006). Motivation in the first accounting course. The CPA Journal, $76(5), 66$.

[14] Villalobos, A., Dulce, A., Fontilar, L., et. al. (2016). Benefits of co-curricular activities to academic performance of financial and management accounting students. Asia Pacific Journal of Education, Arts and Sciences, 3(1), 83-93.

[15] Villamar, A., Gayagoy, M., Matalang, F., \& Catacutan, K. (2020). Usefulness of mathematics subjects in the accounting courses in baccalaureate education. Mathematics and Statistics, 8 (1) 27-31.

[16] Wintre, M. G., \& Yaffe, M. (2000). First-year students' adjustment to university life as a function of relationships with parents. Journal of adolescent research, 15(1), 9-37. 